\title{
Distribution of the euryhaline squid Lolliguncula brevis in Chesapeake Bay: effects of selected abiotic factors
}

\author{
I. K. Bartol ${ }^{1, *}$, R. Mann ${ }^{2}$, M. Vecchione ${ }^{3}$ \\ ${ }^{1}$ Department of Organismic Biology, Ecology, and Evolution, University of California, Los Angeles, 621 Charles E. Young \\ Drive South, Los Angeles, California 90095-1606, USA \\ ${ }^{2}$ School of Marine Science, Virginia Institute of Marine Science, College of William and Mary, Gloucester Point, \\ Virginia 23062, USA
}

${ }^{3}$ National Oceanic and Atmospheric Administration, National Marine Fisheries Service, Systematics Laboratory, National Museum of Natural History, 10th and Constitution NW, Washington, DC 20560, USA

\begin{abstract}
The majority of cephalopods are thought to have limitations arising from physiology and locomotion that exclude them from shallow, highly variable, euryhaline environments. The brief squid Lolliguncula brevis may be a notable exception because it tolerates low salinities, withstands a wide range of environmental conditions, and swims readily in shallow water. Little is known about the distribution of $L$. brevis in Chesapeake Bay, a diverse and highly variable estuary. Therefore, a survey of L. brevis was conducted in the Virginia portion of Chesapeake Bay from 1993 to 1997 using a $9.1 \mathrm{~m}$ otter trawl, and the effects of selected factors on squid presence were assessed using logistic regression analysis. During spring through fall, $L$. brevis was collected over a wide range of bottomwater salinities (17.9 to $35.0 \%$ ), bottom-water temperatures (8.1 to $29.6^{\circ} \mathrm{C}$ ), bottom-water dissolved oxygen levels (1.9 to $14.6 \mathrm{mg} \mathrm{O}_{2} \mathrm{l}^{-1}$ ), and depths (1.8 to $\left.29.9 \mathrm{~m}\right)$, but it was not present in trawls conducted during winter in. L. brevis, especially juveniles $<60 \mathrm{~mm}$ dorsal mantle length (DML), were abundant, frequently ranking in the upper $12 \%$ of overall annual nektonic trawl catches, and during the fall of some years, ranking second to anchovies. The probability of catching a squid increased in Chesapeake Bay at higher salinities and water temperatures, and was much greater in normoxic than in hypoxic waters; these variables had a profound influence on both annual and seasonal variability in distribution. Salinity had the largest influence on squid distribution, with squid being completely absent from the bay when salinity was $<17.9 \%$ and most abundant in the fall when salinity was highest (despite declines in water temperature). Squid were most prevalent at depths between 10 and $15 \mathrm{~m}$. The results of this study suggest that $L$. brevis is an important component of the Chesapeake Bay ecosystem when salinities and water temperatures are within tolerance limits and that unlike other squids, L. brevis may be well-equipped for an inshore, euryhaline existence.
\end{abstract}

KEY WORDS: Squid $\cdot$ Estuaries $\cdot$ Salinity $\cdot$ Water temperature $\cdot$ Dissolved oxygen $\cdot$ Lolliguncula brevis

\section{INTRODUCTION}

Most squids are unable to osmoregulate and tolerate low salinities (Hendrix et al. 1981, Mangum 1991), preventing the vast majority of squids from invading fresh or estuarine waters - 2 significant aquatic habitats

*E-mail: ikbartol@lifesci.ucla.edu where cephalopods are poorly represented. One notable squid, the brief squid Lolliguncula brevis, is the only species of cephalopod frequently found in low-salinity estuaries (Vecchione 1991a), where it tolerates salinities as low as $8.5 \%$ o for brief periods (Laughlin \& Livingston 1982). Within shallow bays and estuaries, there is evidence that $L$. brevis withstands low dissolved oxygen levels (Vecchione 1991b) and a 
wider range of water temperatures than most cephalopods (Hixon 1980, Roper et al. 1984). This species is smaller than most loliginids, seldom reaches sizes greater than $110 \mathrm{~mm}$ in dorsal mantle length (DML) (Hixon 1980, Vecchione et al. 1989), has rounded wide fins, and appears to swim at low velocities (Finke et al. 1996, Bartol et al. 2001a, b). These traits are beneficial for maneuvering in nearshore waters of the Gulf of Mexico and along the western Atlantic coast from Delaware to Brazil, where L. brevis is commonly found (Vecchione et al. 1989).

Little is known about Lolliguncula brevis distribution in Chesapeake Bay. This is surprising, given that $L$. brevis presumably has exceptional tolerance among cephalopods to salinity and other physical conditions and that Chesapeake Bay is one of the largest, most diverse, physically variable estuaries in the world, with tributaries and rivers within the system constituting a shoreline a few thousand kilometers long. Within Chesapeake Bay, physical and biological processes operate rapidly and intensely on many different temporal and spatial scales: large-scale pycnoclines extending almost the entire length of the bay frequently develop throughout the spring (Brandt et al. 1986); significant phytoplankton blooms arise in the late spring/early summer (Pinet 1992); regions of bottom-water hypoxia may develop in the late summer for weeks or even between tides when organic matter deposition is high and vertical mixing is difficult because of water-column stratification (Webb \& D'Elia 1980); hundreds of northern and southern species of fishes converge in the bay throughout the year (Geer \& Austin 1995); and dramatic decreases in salinity and water temperature occur rapidly in the spring and winter, respectively (Brandt et al. 1986). Given that most squids evolved to reside in physically stable, offshore environments where interactions with fishes are low relative to inshore environments (O'Dor \& Webber 1986, Wells 1994), the presence of L. brevis in a highly variable, euryhaline environment rich in nektonic fauna such as Chesapeake Bay is intriguing. Understanding the distribution of $L$. brevis in Chesapeake Bay in relation to physical factors promises insight into the ecology of a unique squid that lives in an environment that tests its physiological limitations.

To learn about the distribution of brief squid in Chesapeake Bay, a survey was conducted in the Virginia portion of the bay from 1993 to 1997 using an otter trawl. The primary objective of this study was to determine what and how selected abiotic factors affect brief squid presence within Chesapeake Bay. The abiotic factors of greatest interest were: tidal stage, bottom depth, salinity, water temperature, dissolved oxygen and water clarity. Since temporal variation in the Chesapeake Bay ecosystem is high, the effects of year and season also were considered. Two secondary objectives of the study were to provide some assessment of the abundance of brief squid in Chesapeake Bay relative to other nekton and to document the size distribution of brief squid in Chesapeake Bay throughout the year.

\section{MATERIALS AND METHODS}

Sampling design. Data on Lolliguncula brevis distribution were collected from 1993 to 1997 during the Virginia Institute of Marine Science (VIMS) Trawl Survey Monitoring Program, which was established to generate annual indices for juvenile marine and estuarine finfish and invertebrates within Virginia waters. During this study, both the mainstem of the lower Chesapeake Bay from the Bay mouth to $37^{\circ} 40^{\prime} \mathrm{N}$ and 3 major Virginia tributaries, the James, York, and Rappahanock Rivers, were sampled (see Fig. 1). The gear used consisted of a $9.1 \mathrm{~m}$ semi-balloon otter trawl with $3.8 \mathrm{~cm}$ body mesh, $3.2 \mathrm{~cm}$ cod-end mesh, $1.3 \mathrm{~cm}$ codend liner mesh, a tickler chain, and steel China-V doors $(71 \mathrm{~cm} \times 48 \mathrm{~cm})$. Each tow lasted $5 \mathrm{~min}$ (bottom time) and was performed at a speed of $1.29 \mathrm{~m} \mathrm{~s}^{-1}$.

A stratified random design with stratification by latitude and water depth was used to sample sites within the Chesapeake Bay mainstem. Three latitudinal strata $\left(36^{\circ} 55^{\prime}-37^{\circ} 10^{\prime} \mathrm{N}_{i} 37^{\circ} 10^{\prime}-37^{\circ} 25^{\prime} \mathrm{N}_{i}\right.$ and $37^{\circ} 25^{\prime}-$ $37^{\circ} 40^{\prime} \mathrm{N}$ ) and 4 depth strata (eastern bay shoal areas [3.6-9.1 m]; western bay shoal areas [3.6-9.1 m]; plain areas [9.1-13 m]; and deep areas [>13 m]) were considered, resulting in a total of 12 strata. The strata were fixed in time and did not change with tidal cycles. Sampling sites were selected randomly within the 12 strata using computerized files of the National Ocean Survey's Chesapeake Bay bathymetric grid system. Sampling within the Chesapeake Bay mainstem was conducted monthly from April through December and in February of each year. Within each of the 3 latitudinal strata for every month considered during a given year, sampling included 4 stations within the plain stratum, 3 stations within the deep stratum, and either 3 (in May through November) or 2 (in December, February, and April) stations within each of the 2 shoal strata. Therefore, 33 to 39 stations were sampled each month (except January and March when no samples were collected) within the mainstem of Chesapeake Bay.

Within the 3 tributaries, fixed stations located in the center of the river channels at $8 \mathrm{~km}$ intervals from the river mouths to the freshwater interfaces were sampled monthly from 1993 to 1997. In 1996 and 1997, additional stations were sampled using a stratified random design partitioned by region and depth. Each river was divided into 4 regions, but the number of 
depth strata (2 to 5) within each region varied according to the dimensions of the tributaries. Generally, 25 to 62 tributary stations were sampled each month within the 3 tributaries.

Bottom depth, bottom-water salinity, bottom-water temperature, bottom-water dissolved oxygen, and Secchi depth (a measure of water clarity) were recorded at all stations immediately following each tow. Bottom depth $( \pm 0.1 \mathrm{~m})$ was measured using an ultrasonic depth sounder, salinity $( \pm 0.1 \%)$, water temperature $\left( \pm 0.1^{\circ} \mathrm{C}\right)$ and dissolved oxygen $\left( \pm 0.1 \mathrm{mg} \mathrm{O} \mathrm{O}_{2} \mathrm{l}^{-1}\right)$ were measured using a Hydrolab multiprobe (Hydrolab Corporation, Austin, Texas); and Secchi depth ( $\pm 0.1 \mathrm{~m})$ was measured using a Secchi disk. Tidal stage was estimated using Chesapeake tidewater tide logs (Pacific Publishers, Bolinas, California) and Tide and Currents Version 2.0 software (Nautical Software, Inc., Beaverton, OR). Latitude and longitude at the beginning and ending of each tow were determined using Loran C conversions or a Global Positioning System (GPS) receiver. Tow distance was defined as the distance between beginning and ending latitude/longitude coordinates.

The number and DMLs of squid and the number and types of vertebrate nekton captured in the trawls were recorded. Occasionally, squid were dissected to characterize the approximate stage of gonad maturity. Male squid were considered mature when they had a well-developed penis, tightly packed spermatophores within the spermatophoric sac, and a yellowish or whitish testis. Female squid were considered ripe when their internal oviduct was filled with mature, amber-colored eggs.

One limitation of the trawl survey data was that squid captured prior to 1997 in Chesapeake Bay were simply classified as squid and assumed to be Lolliguncula brevis. Examinations of squid captured in 1997 and 1998 revealed that several large (>110 mm DML) squid captured in trawls at the Chesapeake Bay mouth in high salinities were Loligo pealei, a loliginid that is typically larger than Lolliguncula brevis, reaching sizes up to $500 \mathrm{~mm}$ DML (Vecchione et al. 1989). The number of squid identified in 1997 and 1998 as Loligo pealei was small relative to those identified as Lolliguncula brevis, however, and no squid less than 110 $\mathrm{mm}$ has been identified to date as Loligo pealei. Since Lolliguncula brevis rarely grows larger than $110 \mathrm{~mm}$ DML (Hixon 1980), all squid $\geq 110$ mm DML were considered to be Loligo pealei and eliminated from the analysis. Conversely, all squid $<110 \mathrm{~mm}$ were considered to be Lolliguncula brevis and included in the analysis. Although this does not guarantee that only $L$. brevis were considered in this study, the number of Loligo pealei in the samples was probably negligible. This assertion is based on: (1) independent trawling performed in the Chesapeake Bay ecosystem for purposes of collecting specimens for separate swimming physiology studies, where 1 out of 1243 squid captured were L. pealei; (2) identifications of present and past trawl-survey specimens, which reveal small numbers of $L$. pealei, and (3) the physiology and ecology of $L$. pealei ( $L$. pealei avoids euryhaline environments, preferring areas $>32 \%$ and $>40 \mathrm{~m}$ [Hixon 1980], which are rare in Chesapeake Bay).

Statistical analysis to assess the effects of selected factors on squid presence. Since the primary objective of this study was to determine what and how selected physical variables influence squid presence within Chesapeake Bay, the outcome or dependent variable was simply the presence or absence of squid at each sampling site and the independent variables were the selected factors of interest (e.g. depth, salinity, etc.). Logistic regression using the logit link, a standard method of analyzing dichotomous, discrete outcome variables (Hosmer \& Lemeshow 1989), was used to model the presence/absence of brief squid in trawl catches. The specific form of the logistic regression model is as follows:

$$
p=\frac{\exp \left(\alpha+\beta_{1} X_{1}+\beta_{2} X_{2} \ldots \beta_{i} X_{i}\right)}{1+\exp \left(\alpha+\beta_{1} X_{1}+\beta_{2} X_{2} \ldots \beta_{i} X_{i}\right)}
$$

where $p=$ event probability (i.e., probability of catching at least 1 squid), $\alpha$ is a constant, $X_{i}$ is an independent variable, $i$ (e.g. salinity, temperature, etc.), and $\beta_{i}$ is a coefficient of the independent variable, $X_{i}$.

The coefficients $(\beta)$ of the variables included in the model are most interpretable when expressed in terms of the odds ratio $(\psi): \psi=\mathrm{e}^{\beta}$. Both scaled continuous and discrete variables are considered in the logistic regression model. For scaled continuous independent variables, the odds ratio $(\psi)$ is a measure of how much more likely (or unlikely if the odds ratio is $<1$ ) it is for the outcome (in this case, the presence of at least 1 squid in a trawl) to be present when the variable is increased by 1 unit. Consequently, the interpretation of a continuous independent variable within a logistic regression model will depend heavily on what scaling units (e.g. $2 \%$ or $2{ }^{\circ} \mathrm{C}$ ) are selected for the variable, and thus selected units should be of biological relevance (Hosmer \& Lemeshow 1989). For example, it may be more biologically informative to determine how catch probabilities vary with every $2^{\circ} \mathrm{C}$ change in water temperature rather than with every $0.2^{\circ} \mathrm{C}$ change when ecological variations may be very slight. Therefore, continuous variables were scaled and coded according to units of reasonable biological relevance and to ensure there was a sufficient sample size in each category level. Continuous variables considered in this analysis with their respective scaling units denoted in parentheses were: bottom depth $(2 \mathrm{~m})$, bottom salinity 
$(2 \%)$, bottom temperature $\left(2{ }^{\circ} \mathrm{C}\right)$, bottom dissolved oxygen $\left(3 \mathrm{mg} \mathrm{O}_{2} \mathrm{l}^{-1}\right.$ ), tow distance $(100 \mathrm{~m})$ and Secchi depth $(0.5 \mathrm{~m})$.

For discrete independent variables, the odds ratio is a measure of how much more likely (or unlikely) it is for the outcome to be present relative to a reference category (Hosmer \& Lemeshow 1989, Agresti 1990). For example, within a discrete variable such as season, the coefficients of fall, summer, and winter may be expressed relative to the coefficient of spring. The discrete variables considered in this analysis were: year (1993, 1994, 1995, 1996, and 1997), season (spring, fall, summer, and winter), and tidal stage (early flood, maximum flood, late flood, slack before ebb, early ebb, maximum ebb, late ebb, and slack before flood).

Two significant findings were detected during the early stages of logistic regression model construction: (1) no squid were caught in trawls during winter, and (2) no squid were caught in areas with salinities below $17.5 \%$. Since there was a zero probability of catching squid in areas sampled during the winter or in waters $<17.5 \%$, all sites meeting these criteria were eliminated and not used in logistic regression models. A total of 2762 sampling sites were eliminated, leaving 2393 sampling sites for consideration within the logistic regression models.

Logistic regression model construction and refinement were performed following procedures suggested by Hosmer \& Lemeshow (1989: Chapter 4). First, univariate logistic regression analyses were performed on each variable. Significance was assessed at $\alpha=0.25$ using the -2 log likelihood estimation chi-square, and non-significant variables were eliminated from consideration. This level of significance, rather than the conventional $\alpha=0.05$ level, was selected to minimize the chance of excluding variables that might be important outcome predictors when considered collectively with other variables in a multivariate analysis (Mickey \& Greenland 1989). At the univariate stage, scaling of discrete variables also was examined; when several categories within a discrete variable had similar coefficients and odds ratios, they were combined to form broader categories (Hosmer \& Lemeshow 1989).

Upon completion of the univariate analyses, all significant variables were included in a multivariate model. Variables that were not significant at the $\alpha=$ 0.05 level within the multivariate model and that did not contribute to wide fluctuations in coefficients after removal were eliminated, and further multivariate logistic regression models were performed. Once all essential variables were determined, the scale of continuous variables was examined so that assumptions of linearity in the logit were not violated. Linearity of scaled continuous variables was examined by dividing values into quartiles (or smaller groupings when higher resolution was necessary) and treating continuous variables as discrete variables in the multivariate model using the lowest quartile (or group) as the reference level. This procedure revealed that it was sometimes necessary to truncate the range of categories within a variable, increase unit size, and treat some scaled continuous variables as discrete and nominal when assumptions of linearity were violated. Although this scaling may reduce resolution within the model, it stabilizes parameter estimates, produces goodness-offit measures of greater reliability, and makes the model more interpretable (Hosmer \& Lemeshow 1989, Agresti 1990).

Once all relevant variables were determined and expressed in the correct scale, further model refinement involved the consideration of interactions. Because of practical considerations, it is not possible to include all interactions in logistic regression models that have many variables. Only those interactions that make biological sense should be investigated (Hosmer \& Lemeshow 1989). Thus, we restricted our search for interactions to those involving the 4 abiotic factors of greatest interest: depth, salinity, water temperature, and dissolved oxygen level. Each interaction involving these factors was added separately to the final, maineffects-only, multivariate model. A determination as to whether to include the interaction in further models was based on both the significance of the -2 log likelihood estimation of the new model and the p-value of the interaction. Interactions that were significant at $\alpha=$ 0.05 and that provided significant improvement over the main-effects-only model were added to the final model. To decouple the effects of factors involved in significant interactions, logits for all factor combinations were computed and significance assessed at $\alpha=0.05$ using procedures described in detail on p. 102-106 of Hosmer \& Lemeshow. The fit of the final, most parsimonious model was assessed using Hosmer and Lemeshow goodness-of-fit tests and various logistic regression diagnostics (Hosmer \& Lemeshow 1989: p 149-170). There was no overdispersion in the model, i.e., data did not deviate significantly from the expected binomial distribution.

NMFS/NEFSC bottom trawl surveys. Size distribution and catch location data on Lolliguncula brevis collected during spring and autumn bottom-trawl surveys by the National Marine Fisheries Service (NMFS)/Northeast Fisheries Science Center (NEFSC) for 1993 to 1997 were considered in this study. These surveys were conducted within coastal waters (30 to $1200 \mathrm{~m}$ ) of the Atlantic Ocean from Cape Hatteras, North Carolina, to the Gulf of Maine. Approximately 300, 30 min tows were performed biannually at randomly selected sites using a \#36 otter trawl with a $1.26 \mathrm{~cm}$ cod-end mesh liner. Dorsal mantle lengths of 
L. brevis captured in each tow were recorded, and capture location and depth were noted. Further information on NMFS/NEFSC bottom-trawl procedures may be found in 'Fisherman's Reports' for 1993 to 1997 (NMFS, NEFSC, Woods Hole, Massachusetts 02543) and at: http://www.nefsc.nmfs.gov/sos/vesurv /vesurv.html.

\section{RESULTS}

Lolliguncula brevis was captured at 545 of the 5155 sampling sites. In trawls containing squid, the mode was 1 squid caught per trawl, the median was 4 squid caught per trawl, the mean was $16.2 \pm 31.9(\mathrm{SD})$ squid caught per trawl, and the range was 1 to 325 squid caught per trawl. The majority of $L$. brevis captured during the survey were collected in the mainstem of Chesapeake Bay and not the tributaries, and the greatest overall number of squid collected in trawls occurred within the central channel of the lower bay and along the eastern portion of the bay (Fig. 1). L. brevis were captured during spring, summer, and fall, but no squid were captured in trawls conducted during winter. Estuarine waters of 0.9 to $43.9 \mathrm{~m}, 0.0$ to $37.1 \%$, 0.3 to $31.0^{\circ} \mathrm{C}, 0.1$ to $14.6 \mathrm{mg}$ $\mathrm{O}_{2} \mathrm{l}^{-1}$, and were sampled; brief squid were collected over a wide range of depths (1.8 to $29.9 \mathrm{~m}$ ), bottom-water salinities (17.9 to $35.0 \%$ ), bottomwater temperatures $\left(8.1\right.$ to $\left.29.6^{\circ} \mathrm{C}\right)$, and bottom-water dissolved oxygen levels (1.9 to $14.6 \mathrm{mg} \mathrm{O}_{2} \mathrm{l}^{-1}$ ).

In terms of overall numbers of animals caught annually in trawls, Lolliguncula brevis ranked 9 out of 94 total fish/squid species in 1993 (90th percentile), 18 out of 92 total fish/squid species in 1994 (80th percentile), 6 out of 94 total fish/squid species in 1995 (94th percentile), 46 out of 98 total fish/squid species in 1996 (53rd percentile), and 12 out of 103 total fish/ squid species in 1997 (88th percentile). When distinctions are made between Chesapeake Bay mainstem and tributary sites, it is clear that squid ranked consistently higher annually within the Chesapeake Bay mainstem than within the tributaries (Fig. 2). Moreover, squid generally ranked higher in the summer and fall than in the winter and spring both in the Chesapeake Bay mainstem and the tributaries. Brief squid were especially abundant within the Chesapeake Bay mainstem during the fall of 1995, when squid ranked second (behind bay anchovies Anchoa mitchilli) out of 53 (96th percentile) squid/fish caught (Fig. 2).

Most of the squid captured during this survey were $<60 \mathrm{~mm}$ DML, although some larger squid ( $\geq 70 \mathrm{~mm}$ DML) were present in the spring of most years (i.e.,

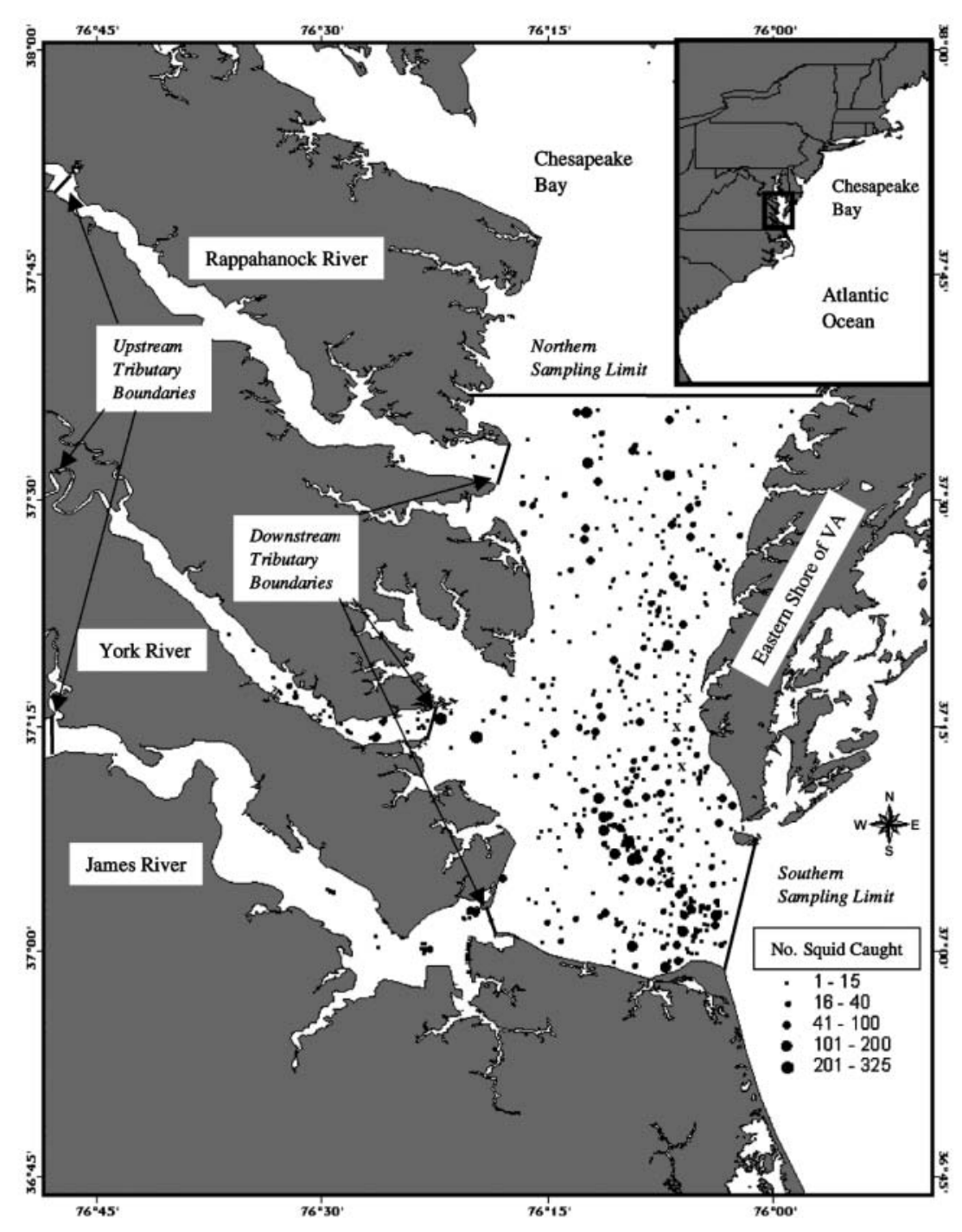

Fig. 1. Map of Chesapeake Bay study site. Mainstem of lower Chesapeake Bay from the bay mouth (southern sampling limit) to $37^{\circ} 40^{\prime} \mathrm{N}$ (northern sampling limit) and 3 Virginia tributaries, the James, York, and Rappahanock Rivers, were sampled. Upstream and downstream tributary boundaries are depicted. Number of brief squid Lolliguncula brevis captured in trawls from 1993 to 1997 in Chesapeake Bay are shown (circles) as well as locations where egg capsules were found (x). All squid in this figure were $<110 \mathrm{~mm}$ in dorsal mantle length. Each tow lasted $5 \mathrm{~min}$ (bottom time) and was performed at a speed of $9.7 \mathrm{~km}^{-1} \mathrm{~h}$ 

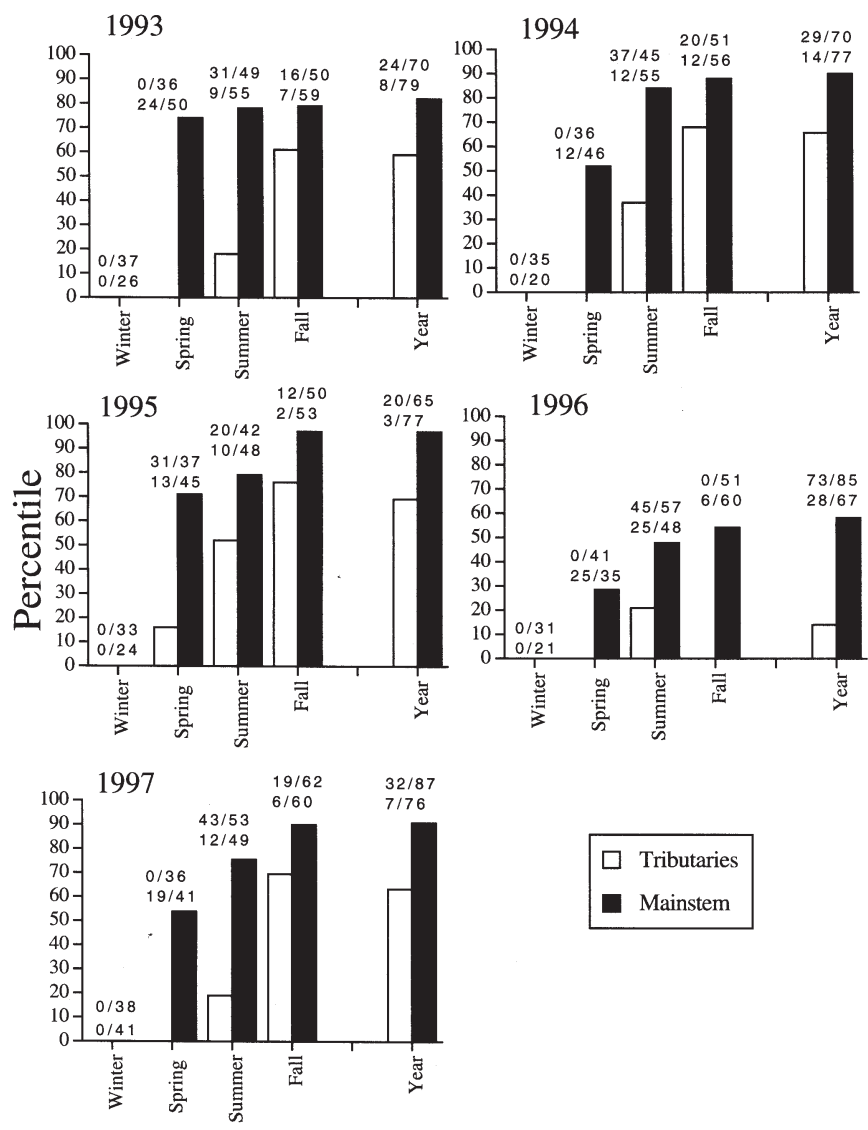

1993, 1995, 1996, 1997) and comprised a noticeable proportion of spring catches (Fig. 3). The mean DML of squid decreased from spring to summer in each year of the study. However, with the exception of 1994, when size increased substantially from summer to fall, there was little difference in the mean DML of squid caught in summer and fall. In contrast, a clear increase in Lolliguncula brevis mantle length from spring to fall was observed in coastal waters from Delaware to Florida in NMFS/NEFSC surveys. In these surveys, mean $L$. brevis DML was $32 \mathrm{~mm}$ DML $( \pm 12 \mathrm{SD})$ during the spring and 62 mm DML ( $\pm 23 \mathrm{SD})$ during the fall (Fig. 4). In the NMFS/NEFSC surveys, $L$. brevis were caught in depths shallower than $36 \mathrm{~m}$, with the

Fig. 3. Lolliguncula brevis. Length/frequency data of brief squid captured in spring, summer, and fall during the VIMS trawl surveys from 1993 to 1997. Annual data as well as cumulative data for the entire sampling period (lower right graph) are depicted. For each of the 3 seasons, proportion of total catches within each of 11 size classes is presented. Total number (n) and mean dorsal length (m) of squid caught within the 3 seasons are included above the graphs

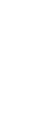

Fig. 2. Lolliguncula brevis. Seasonal (winter, spring, summer, and fall) and annual (year) rankings for brief squid caught by trawl in mainstem and tributary sections of Chesapeake Bay in 1993 to 1997. Rankings are expressed as percentiles and are based on the total number of brief squid caught relative to the total number of each fish species caught per season or per year at mainstem and tributary regions of Chesapeake Bay. Fractions above bars denote the exact rank of squid out of the total number of squid/fish species considered: lower fractions are results from mainstem stations, upper fractions for tributary stations

majority of squid being caught in waters shallower than $23 \mathrm{~m}$.

Tow distance and Secchi depth did not significantly influence the probability of catching at least 1 squid in a trawl, and were thus eliminated from the final logistic regression model. The factors and respective categories considered in the final, most parsimonious model are shown in Table 1. The logistic regression model was highly significant ( -2 log-likelihood chi square $=-786.15 ;$ goodness-of-fit statistic, $G=665.28$; $\mathrm{df}=15 ; \mathrm{p}<0.001)$, and the model adequately fit the data (Hosmer \& Lemeshow test, p = 0.359) (Table 1).
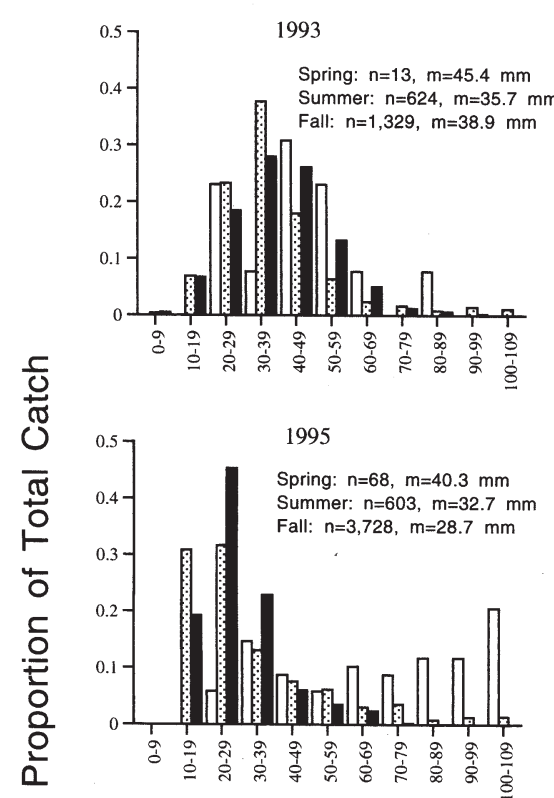
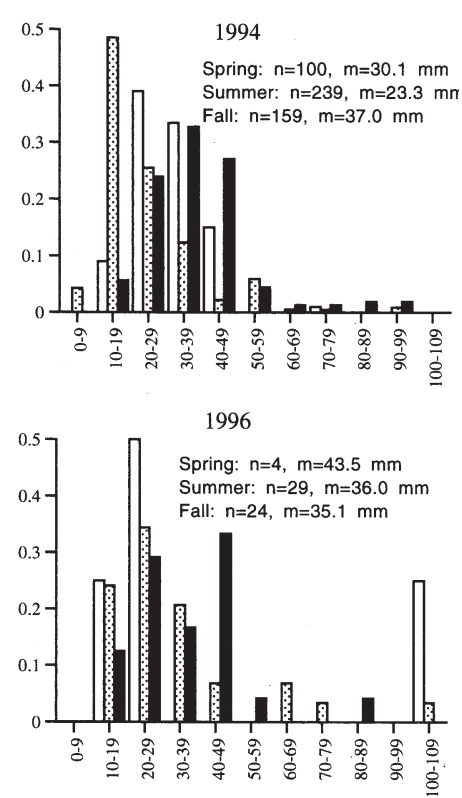

1993-1997

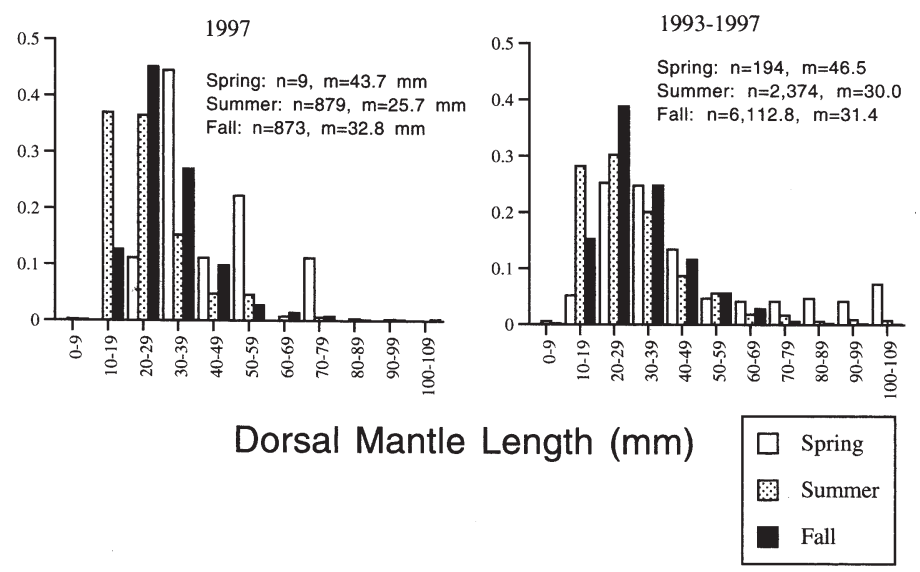

Dorsal Mantle Length $(\mathrm{mm})$ 


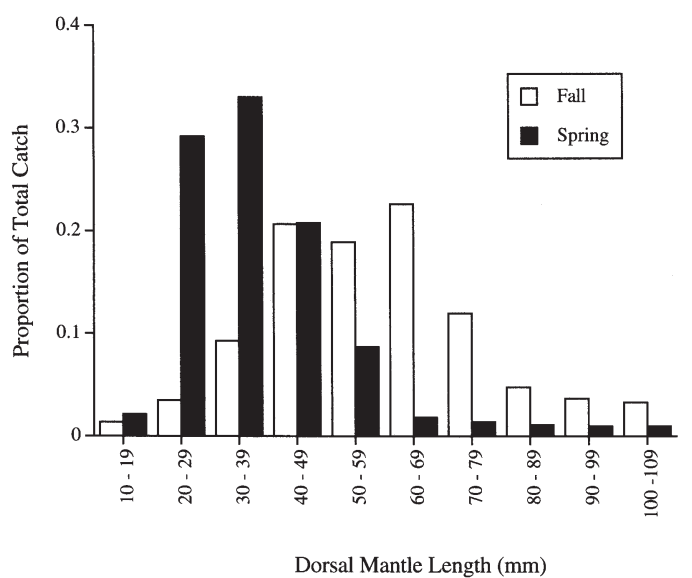

Fig. 4. Lolliguncula brevis. Length/frequency data of squid collected during spring and fall NMFS/NEFSC surveys (1993 to 1997) along the coastline of the US from Delaware to Florida. Proportion of total spring and fall catches within each of 10 size classes is presented. In the fall survey 518 squid were caught, in the spring survey 713 squid

Tidal stage and depth affected capture probability. The probability of catching a squid was significantly less during maximum flood/maximum ebb $(p<0.001$; $\psi=0.56)$ and late flood through early ebb $(\mathrm{p}=0.010$; $\psi=0.67$ ) than during late ebb through early flood (Table 1). The probability of catching a squid increased with depth to a point after which there was no detectable difference in squid catch probability; there was significantly higher probability of catching a squid at depths of 5.0 to $9.9 \mathrm{~m}$ than at depths $<5.0 \mathrm{~m}(\mathrm{p}=$ $0.001 ; \psi=2.16$ ) and an even higher probability of catching a squid at depths between 10.0 and $14.9 \mathrm{~m}$ than at depths $<5.0 \mathrm{~m}(\mathrm{p}<0.001 ; \psi=3.62)$, but no significant difference in catch probability was detected when depths $\geq 15.0 \mathrm{~m}$ were compared with depths $<5.0$ $\mathrm{m}(\mathrm{p}=0.316)$ (Table 1).

Salinity $(\mathrm{p}<0.001 ; \psi=4.26)$ and water temperature ( $p<0.001 ; \psi=2.42$ ) had significant impacts on squid catch probability, although the effects were confounded by a water temperature $\times$ salinity interaction ( $p<0.001 ; \psi=0.91$ : Table 1$)$. Logit comparisons of all water temperature/salinity combinations revealed that only at low temperatures $\left(5\right.$ to $9^{\circ} \mathrm{C}$ ) did the probability of catching at least one squid not increase significantly with increased salinity (Fig. 5). Otherwise, the probability of catching at least 1 squid generally increased with increased salinity and water temperature. When both salinity and water temperature were high, there was about a $70 \%$ probability of catching a squid in a

Table 1. Lolliguncula brevis. Multivariate logistic regression table of squid presence/absence within the Chesapeake Bay. Five discrete factors (tide, depth, dissolved oxygen, year, and season), 2 scaled continuous factors (salinity and water temperature) and 1 interaction (water temperature $\times$ salinity) are included in the model. Reference levels (r) and incremental units (u) are included in parentheses next to discrete and scaled continuous factors, respectively. The logistic regression model was highly significant: -2 log-likelihood $=-786.15$; goodness-of-fit statistic, $G=665.28, \mathrm{df}=15, \mathrm{p}<0.001$. Goodness-of-fit $($ Hosmer-Lemeshow method) $=$ chi-square $8.804 ; \mathrm{df}=8 ; \mathrm{p}=0.359$

\begin{tabular}{|c|c|c|c|c|c|c|}
\hline Predictor & Coefficient & $Z$-value & $\mathrm{p}$-value & $\begin{array}{l}\text { Odds } \\
\text { ratio }(\psi)\end{array}$ & $\begin{array}{c}\text { Lower } 95 \% \\
\text { CI }\end{array}$ & $\begin{array}{l}\text { Upper } 95 \% \\
\text { CI }\end{array}$ \\
\hline Constant & -15.836 & -12.62 & $<0.001$ & & & \\
\hline \multicolumn{7}{|l|}{ Tide ( $\mathrm{r}=$ late ebb - early flood) } \\
\hline Max. flood / max. ebb & -0.577 & -3.63 & $<0.001$ & 0.56 & 0.41 & 0.77 \\
\hline Late flood - early ebb & -0.402 & -2.59 & 0.010 & 0.67 & 0.49 & 0.91 \\
\hline \multicolumn{7}{|l|}{ Depth $(\mathrm{r}=0.0-4.9 \mathrm{~m})$} \\
\hline $5.0-9.9 \mathrm{~m}$ & 0.771 & 3.22 & 0.001 & 2.16 & 1.35 & 3.46 \\
\hline $10.0-14.9 \mathrm{~m}$ & 1.286 & 5.27 & $<0.001$ & 3.62 & 2.24 & 5.83 \\
\hline$\geq 15.0 \mathrm{~m}$ & 0.302 & 1.00 & 0.316 & 1.35 & 0.75 & 2.44 \\
\hline Salinity $(\mathrm{u}=2 \%$ ) & 1.449 & 7.02 & $<0.001$ & 4.26 & 2.84 & 6.38 \\
\hline Water temperature $\left(\mathrm{u}=3^{\circ} \mathrm{C}\right)$ & 0.884 & 6.63 & $<0.001$ & 2.42 & 1.86 & 3.14 \\
\hline \multicolumn{7}{|c|}{ Dissolved oxygen $\left(\mathrm{r}=<3 \mathrm{mg} \mathrm{O}_{2} \mathrm{l}^{-1}\right)$} \\
\hline \multicolumn{7}{|l|}{ Year $(\mathrm{r}=1996)$} \\
\hline 1993 & 1.084 & 3.86 & $<0.001$ & 2.96 & 1.70 & 5.13 \\
\hline 1994 & 0.927 & 3.30 & 0.001 & 2.53 & 1.46 & 4.38 \\
\hline 1995 & 1.816 & 6.87 & $<0.001$ & 6.15 & 3.66 & 10.32 \\
\hline 1997 & 1.266 & 4.79 & $<0.001$ & 3.54 & 2.11 & 5.95 \\
\hline \multicolumn{7}{|l|}{ Season $(\mathrm{r}=$ spring $)$} \\
\hline Summer & 0.934 & 3.57 & $<0.001$ & 2.55 & 1.52 & 4.25 \\
\hline Fall & 2.494 & 11.07 & $<0.001$ & 12.11 & 7.79 & 18.83 \\
\hline Water temperature $\times$ Salinity & -0.099 & -3.49 & $<0.001$ & 0.91 & 0.86 & 0.96 \\
\hline
\end{tabular}


trawl (Fig. 5). Based on the odds ratios where catch probability increased by a factor of 4.26 with every $2 \%$ rise (between 17.5 and $37.1 \%$ ) and by a factor of 2.42 with every $3^{\circ} \mathrm{C}$ rise (between 5 and $30^{\circ} \mathrm{C}$ ), salinity had a larger influence on catch probability than water temperature.

Dissolved oxygen was treated as a dichotomous discrete variable because the only clear difference in catch probability occurred between normoxic and hypoxic sites (i.e., no linear or quadratic relationships between the logit and dissolved oxygen levels were present). Not surprisingly, catch probability increased dramatically ( $\mathrm{p}<0.001 ; \psi=10.88$ ) when sampling in normoxic as opposed to hypoxic waters.

Capture probability varied both annually and seasonally. The probability of catching a squid was lowest in 1996 and highest in 1995, when the probability of catching a squid was 6.15 times greater than in 1996 (Table 1). There was a 2.55 times greater probability of catching a squid in summer than in spring, and a 12.11 times greater probability of catching a squid in fall than in spring (Table 1).

There was considerable annual and seasonal variation in physical conditions over the period of this study. In 1995, when the probability of catching a squid was highest, mean monthly bottom-water salinities for all stations sampled did not decline below $18.5 \%$ ( $\pm 7.3 \mathrm{SD})$, even

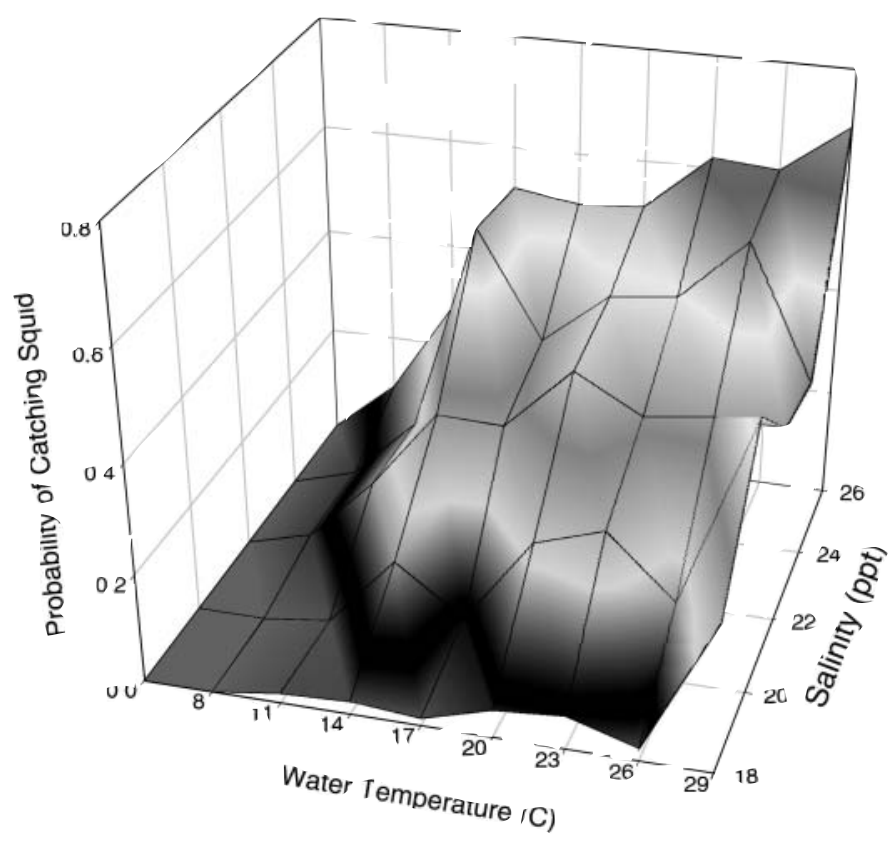

Fig. 5. Lolliguncula brevis. Probability of catching at least 1 squid in a trawl plotted as a function of salinity and water temperature. Generally, probabilities are enhanced with increasing salinity and temperature; however, when water temperatures are $\leq 9^{\circ} \mathrm{C}$, catch probability does not increase with increasing salinity

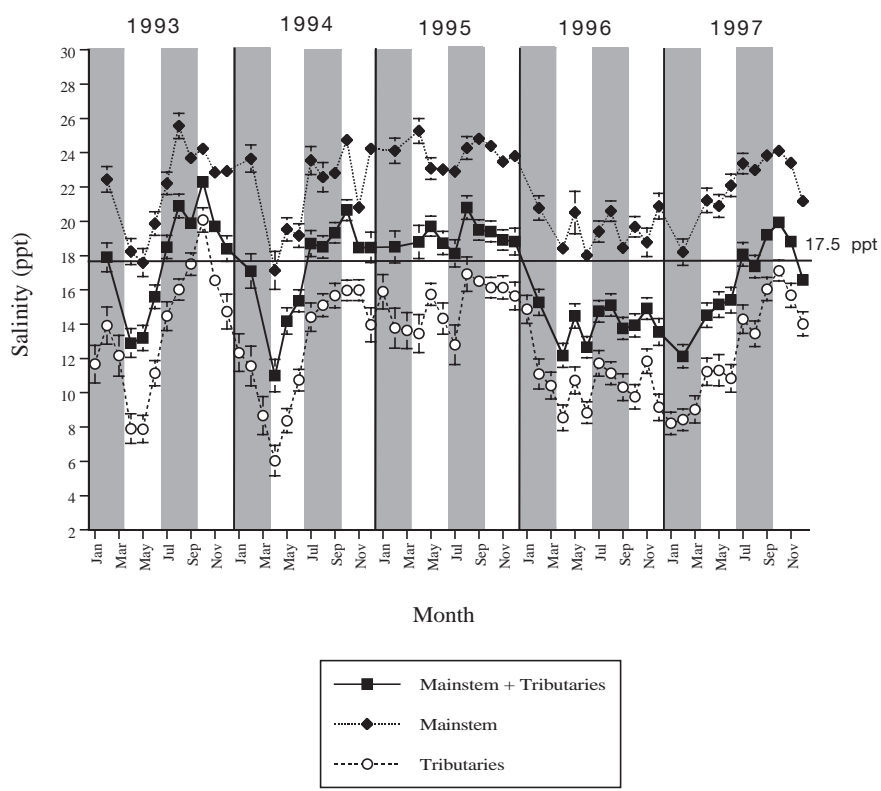

Fig. 6. Mean ( $\pm 1 \mathrm{SE})$ monthly bottom-water salinities at sampling sites during VIMS Trawl Surveys from 1993 to 1997. Mean monthly salinities for all stations sampled (Mainstem and Tributaries), Chesapeake Bay mainstem sampling sites (Mainstem), and tributary sampling sites (Tributaries) are plotted; $17.5 \%$ line: lower physiological limit of brief squid salinity tolerance; shaded areas: winter and summer months; unshaded areas: spring and fall months

during the winter and spring, and mean monthly bottomwater salinities for mainstem Chesapeake Bay stations remained above $22.9 \%$ ( $\pm 3.3 \mathrm{SD}$ ) (Fig. 6). Furthermore, mean monthly bottom-water temperatures for all stations sampled were higher from June through October of 1995 than during these months in other years (Fig. 7). In 1996, when the probability of catching a squid was lowest, mean monthly bottom-water salinities for all stations remained below $15.3 \%$ ( $\pm 6.4 \mathrm{SD})$, and mean monthly bottom-water salinities for bay mainstem stations were $\leq 20.7 \%$ ( \pm 4.1 SD: Fig. 6 ).

During the winter, bottom-water temperatures were routinely below $8^{\circ} \mathrm{C}$, overall mean salinity often decreased relative to conditions in the fall, and dissolved oxygen levels were the highest of the year (Figs. 6 to 8). In the spring, overall mean salinities often were below $17.5 \%$, with the notable exception of 1995 when overall mean salinities did not decrease below $18.5 \%$ for the entire year. Relative to conditions in the winter, dissolved oxygen levels decreased and water temperatures increased in the spring. In the summer, salinities increased relative to those in spring, water temperatures were clearly the highest of the year, and dissolved oxygen levels were the lowest of the year. In most years, overall mean salinity was greater during the fall than at any other time during the year. Relative to the 

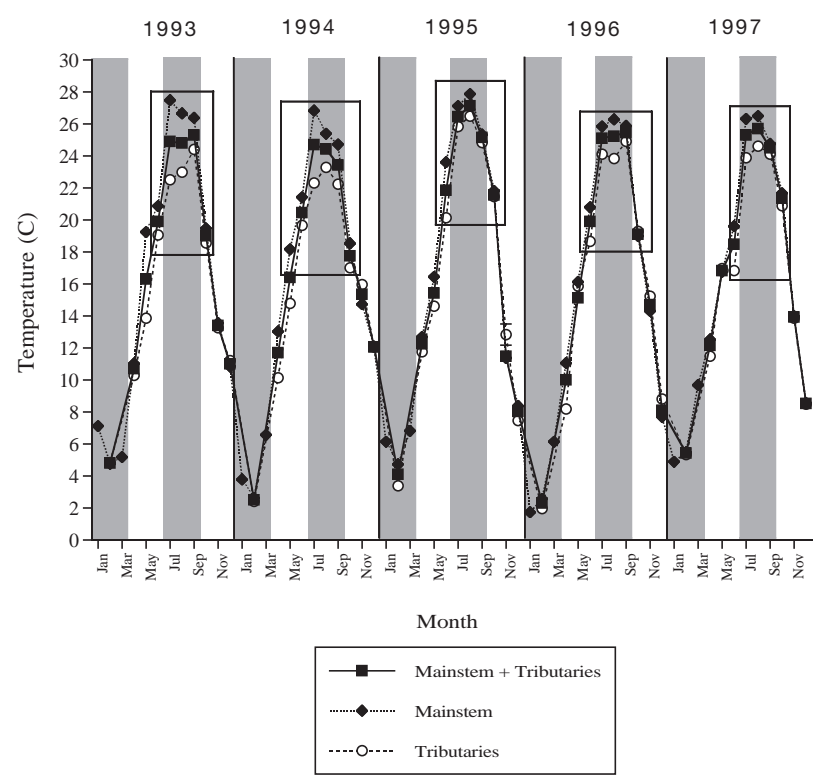

Fig. 7. Mean ( $\pm 1 \mathrm{SE})$ monthly bottom-water temperatures at sampling sites during VIMS trawl surveys from 1993 to 1997. Mean monthly temperatures for all stations sampled (Mainstem and Tributaries), Chesapeake Bay mainstem sampling sites (Mainstem), and tributary sampling sites (Tributaries) are plotted. Boxes: conditions from June-October; shaded areas: winter and summer months; unshaded areas: spring and fall months. Since there was little variability in water temperature between sites during a given month, standard error bars are not always visible

summer, water temperatures decreased and dissolved oxygen levels increased during the fall (Figs 6 to 8).

During the course of this study, Lolliguncula brevis egg masses were occasionally observed within the trawl mesh. These masses were collected in September and October within sandy bottom habitats along the eastern portion of the Chesapeake Bay mainstem (Fig. 1). Individual egg cases were generally $<2.5 \mathrm{~cm}$ in length and contained $<30 \mathrm{~L}$. brevis paralarvae. Furthermore, mature males and ripe females were observed in late July to September.

\section{DISCUSSION}

Salinity, water temperature, and dissolved oxygen levels all play critical roles in determining Lolliguncula brevis distribution in Chesapeake Bay. The data in this study indicate that there are salinity $(17.9 \%$ ) and water temperature $\left(8.1^{\circ} \mathrm{C}\right)$ thresholds below which $L$. brevis is absent from Chesapeake Bay. There is also a level of dissolved oxygen ( $3 \mathrm{mg} \mathrm{O}_{2} \mathrm{l}^{-1}$ ) below which $L$. brevis presence decreases dramatically; however, L. brevis is found in Chesapeake Bay waters with as low as $1.9 \mathrm{mg}$ $\mathrm{O}_{2} \mathrm{I}^{-1}$. Above salinity and water temperature thresh-

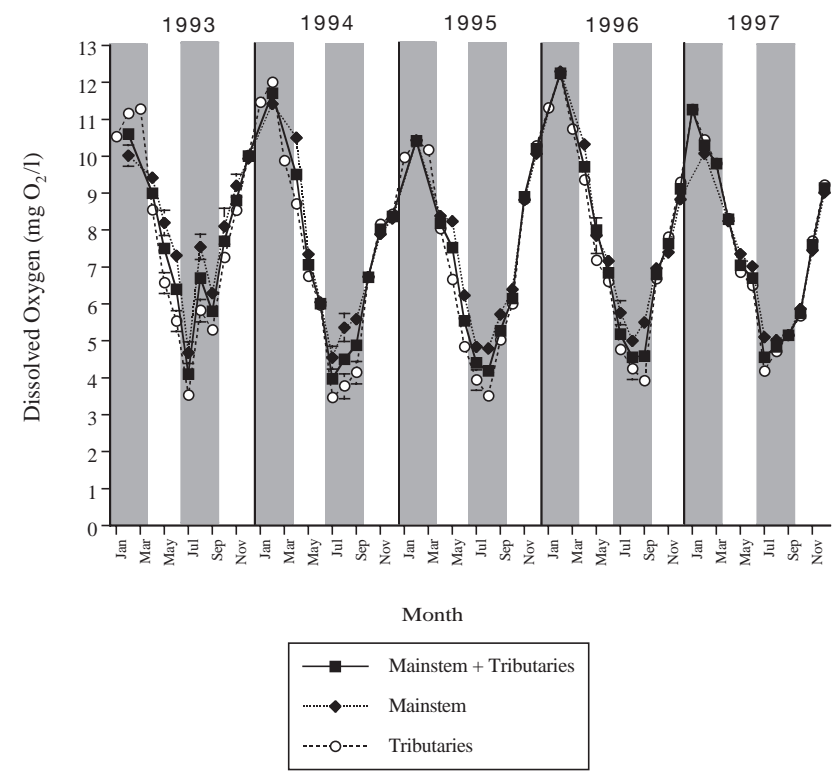

Fig. 8. Mean $( \pm 1 \mathrm{SE})$ monthly dissolved oxygen levels of bottom-water at sampling sites during VIMS trawl surveys from 1993 to 1997. Mean monthly dissolved oxygen levels for all stations sampled (Mainstem and Tributaries), Chesapeake Bay mainstem sampling sites (Mainstem), and tributary sampling sites (Tributaries) are plotted. Shaded areas: winter and summer months; unshaded areas: spring and fall months

olds, the probability of catching a squid increases steadily with increased salinity and water temperature up to conditions of $35 \%$ and $29.6^{\circ} \mathrm{C}$, respectively. In normoxic waters (3.0 to $14.6 \mathrm{mg} \mathrm{O}_{2} \mathrm{l}^{-1}$ ), as opposed to hypoxic waters $\left(<3.0 \mathrm{mg} \mathrm{O} \mathrm{O}^{-1}\right)$, the probability of catching a squid increases by a factor of 10 . Consequently, seasonal and annual variation in one or more of these factors has a significant impact on squid distribution in Chesapeake Bay.

The physical limits detected in this study are consistent with those in previous studies on Lolliguncula brevis, and provide further evidence that this euryhaline squid has exceptional tolerance limits relative to other cephalopods. In controlled laboratory studies, Hendrix et al. (1981) determined that $L$. brevis tolerates salinities down to $17.5 \%$, a limit close to that detected in the present study and below which $L$. brevis demonstrates signs of hypoosmotic stress. The respiratory pigment of $L$. brevis, hemocyanin, is insensitive to salinity changes, has high oxygen affinity, and has little $\mathrm{pH}$ dependence over a broad range of salinities - characteristics that are important for life in euryhaline waters. Conversely, hemocyanin in stenohaline squid, e.g. Loligo pealei, is sensitive to salinity changes, has relatively low oxygen affinity, and has large $\mathrm{pH}$ dependence, preventing these squids from entering lowsalinity areas for extended periods (Mangum 1991). The salinity limit determined in the present study is in 
reasonable agreement with the field-salinity limits of $18.2 \%$ determined by Dragovich \& Kelly (1967) along the western coast of Florida and $20.0 \%$ determined by Hixon (1980) in the northwest Gulf of Mexico. A lower limit of $8.5 \%$ was reported by Laughlin \& Livingston (1982) in an estuary in north Florida, however. The low-end salinity thresholds reported in the present study and in previous studies are lower than those documented for other squids in the north Atlantic, such as L. pealei, L. plei, and Illex illecebrosus, which are typically found in waters $>30 \%$ o (O'Dor et al. 1977, Hixon 1980).

In the Gulf of Mexico, Dragovich \& Kelly (1967), Hixon (1980) and Laughlin \& Livingston (1982) captured Lolliguncula brevis in waters of 12.6 to $31.6^{\circ} \mathrm{C}$, 11 to $31^{\circ} \mathrm{C}$, and 15 to $31^{\circ} \mathrm{C}$, respectively. The results of the present study reveal that $L$. brevis may be found in slightly cooler waters near the northern limit of its range. In a study on the respiratory and cardiac function of $L$. brevis performed in circulating and non-circulating respirometers, Wells et al. (1988) determined that $L$. brevis functions well at water temperatures 14 to $27^{\circ} \mathrm{C}$. Although Wells et al. did not report on the physiology of $L$. brevis below $14^{\circ} \mathrm{C}$, they did find that $L$. brevis demonstrates clear signs of stress, such as decreased heartbeat frequency and increased stroke volume, at higher water temperatures $\left(27\right.$ to $\left.30^{\circ} \mathrm{C}\right)-$ temperatures at which the squid were frequently caught during the present study. Wells et al. attributed the ability of $L$. brevis to tolerate water temperatures up to $31^{\circ} \mathrm{C}$ in nature to long acclimation periods. Loligo plei has a wide range of temperature tolerances (13 to $30^{\circ} \mathrm{C}$ ), like that of Lolliguncula brevis, but most squids have more restricted temperature ranges, e.g. Illex illecebrosus and Loligo pealei, which are found predominantly in waters of 8 to $15^{\circ} \mathrm{C}$ and 7 to $22^{\circ} \mathrm{C}$, respectively (Hixon 1980, Whitaker 1980, Roper et al. 1984).

The discovery of Lolliguncula brevis in hypoxic waters of Chesapeake Bay is consistent with previous studies, and distinguishes $L$. brevis from other squids. Vecchione \& Roper (1991) observed L. brevis in hypoxic waters $\left(0.7 \mathrm{mg} \mathrm{O} \mathrm{O}^{-1}\right)$ of the western North Atlantic using remotely operated submersibles, and Vecchione (1991b) documented L. brevis in hypoxic waters $\left(<3 \mathrm{mg} \mathrm{O}_{2} \mathrm{l}^{-1}\right)$ within coastal and estuarine waters of southwestern Louisiana during trawl surveys. The unique characteristics of the hemocyanin of L. brevis, especially its high $\mathrm{O}_{2}$ affinity, and the ability of $L$. brevis to build up large oxygen debts (unlike other coastal squids) are beneficial for L. brevis in waters with low dissolved oxygen levels (Mangum 1991, Finke et al. 1996). Wells et al. (1988) determined that $L$. brevis activity levels generally decrease when dissolved oxygen levels are $<3 \mathrm{mg} \mathrm{O}_{2} \mathrm{l}^{-1}$, but they found that some $L$. brevis show no behavioral changes down to levels of $2 \mathrm{mg} \mathrm{O}_{2} \mathrm{l}^{-1}$. Because energy availability for cellular ATPases declines rapidly under hypoxic conditions, Finke et al. (1996) and Zielinski et al. (2000) suggested that $L$. brevis may spend only brief periods in hypoxic waters. Excursions by L. brevis into hypoxic waters, however short in duration, may be performed to exploit a food niche or avoid predation as proposed by Vecchione (1991a). Two possible fishes upon which L. brevis may prey in hypoxic waters (provided they are within the proper size range [i.e., length of squid arms or less]) are the spot Leiostomus xanthurus and the Atlantic croaker Micropongonias undulatus - the fishes most commonly encountered in such waters during VIMS Trawl Surveys

The synergistic and independent effects of salinity, water temperature and dissolved oxygen, which all increase catch probabilities when elevated, drive seasonal and annual distribution patterns in Chesapeake Bay. Although high dissolved oxygen levels were observed throughout Chesapeake Bay during the winter, salinity decreased (relative to conditions in the fall) and water temperature dropped below $8^{\circ} \mathrm{C}$, triggering an exodus of Lolliguncula brevis from the bay. When water temperatures increased to approximately $10^{\circ} \mathrm{C}$ in April and May (spring), squid re-entered Chesapeake Bay in areas where salinity was $>17.5 \%$. Similar migratory responses of $L$. brevis to water temperatures were reported by Hixon (1980), who found that $L$. brevis move offshore from Galveston Bay, Texas, in December through February, when mean water temperatures are 12.8 to $13.9^{\circ} \mathrm{C}$, and re-enter inshore bay habitats in March, when temperatures are above $15^{\circ} \mathrm{C}$. The extent to which $L$. brevis enters Chesapeake Bay in the spring and throughout the year depends heavily on salinity. In years when salinity was low throughout the year, e.g. 1996, squid entered Chesapeake Bay later (May as opposed to April), were captured less in trawls, and were found exclusively in the lower, highsalinity regions of the bay. In years when salinity was high in the spring and throughout the year, e.g. 1995, squid entered Chesapeake Bay early (April as opposed to May), were more prevalent in trawls, and were captured in a wider region of the bay. High water temperatures from June through October also contributed to the observed high catch probabilities in 1995.

High salinity and water temperatures or high salinity alone contributed to greater squid catch probabilities in the summer and fall than in the winter and spring. Given that squid catch probabilities were highest in the fall, when waters were less hypoxic, often more saline, but cooler relative to waters during the summer, it appears that the benefits of high salinity and more widespread normoxia outweigh the disadvantages of lower water temperatures. This is not surprising considering the fact that salinity had a greater impact on 
squid catch probability than water temperature in the logistic regression model, and hypoxic water lowers catch probabilities substantially. Laughlin \& Livingston (1982) also found that the spatial distribution of brief squid within a Florida estuary is strongly influenced by salinity as well as habitat structure, while temperature plays a lesser role. Interestingly, in non-estuary settings where salinity does not fluctuate as significantly, there is considerably less seasonal variation in the frequency of occurrence of loliginids (Whitaker 1980).

The regions where squid were encountered most frequently (i.e., central Chesapeake Bay near the mouth and along eastern portions of the bay where waters are deepest and heavily influenced by intruding salt wedges) typically have the highest salinities throughout the year. Consequently, salinity assuredly played an important role in the observed distribution patterns; however, depth played a significant role as well. Brief squid are shallow-water cephalopods, preferring habitats $<30 \mathrm{~m}$ in Galveston Bay, Texas (LaRoe 1967, Hixon 1980) and along the eastern US coast, as shown in the NMFS/NEFSC surveys. The bathymetry of Chesapeake Bay is predominantly $<20 \mathrm{~m}$, and consequently the bay provides optimal depths for squid residence. The data presented is this study indicate that there are further preferences at depths less than $30 \mathrm{~m}$ within the Chesapeake Bay ecosystem, with squid favoring depths of 10 to $15 \mathrm{~m}$ even over deeper waters, which are more saline but also more hypoxic. These depths are found in the central channels of Chesapeake Bay-areas where the highest overall number of squid were encountered. Therefore, when salinities and water temperatures are within tolerance limits, brief squid prefer central channel areas 10 to 15 $\mathrm{m}$ in depth. Laughlin \& Livingston (1982) found a similar preference for channels by brief squid in Appalachicola estuary, Florida.

The higher catch probability observed during late ebb through early flood compared with maximum flood/maximum ebb or late flood through early ebb raises some interesting questions. This result may be, in part, a product of a reduction in water volume within the Chesapeake Bay ecosystem and the consequent concentration of squid communities, resulting in easier entrapment of squid in trawls. However, it also probably reflects a behavioral preference. Lolliguncula brevis swims at low speeds; it has a critical swimming speed of $<25 \mathrm{~cm} \mathrm{~s}^{-1}$, and demonstrates parabolic oxygen consumption curves as a function of speed, with oxygen consumption minima at low/intermediate speeds ( 6 to $12 \mathrm{~cm} \mathrm{~s}^{-1}$ : Bartol et al. $2001 \mathrm{a}, \mathrm{b}$ ). Consequently, lower currents associated with late ebb though early flood tides may be advantageous for maneuvering in the bay environment and for keeping pace with the oncoming current (hovering), which is frequently observed by squids in nature (O'Dor et al. 1994). Given that Laughlin \& Livingston (1982) found $L$. brevis to be more abundant in deep channels where currents are higher than in shallow $(<4 \mathrm{~m})$, enclosed regions, there may be a lower limit to flow velocity, with L. brevis seeking out currents matching optimal swimming speeds, as reported for other squids ( $\mathrm{O}^{\prime} \mathrm{Dor}$ et al. 2001). One important question not addressed directly in the study is: where do squid go during tidal cycles when catch probabilities are low? Given that trawls conducted in this survey sampled only the lower water column of the Chesapeake Bay system, it is conceivable that squid swam higher in the water column during the different tidal phases or simply swam out to sea. Future study, possibly involving the deployment of autonomous underwater vehicles (AUVs), is necessary to determine squid movements and behaviors within Chesapeake Bay as a function of tidal phase and flow speed.

Brief squid are clearly abundant in Chesapeake Bay relative to other nekton captured in the VIMS trawl surveys from 1993 to 1997, ranking in the upper 6 to $12 \%$ of nektonic catches in terms of total number of organisms captured in 3 of the 5 sampling years and in the upper $20 \%$ in all years but 1996 . Moreover, during the fall of some years, squid ranked second to bay anchovies. The results of this study indicate that 2 size classes of Lolliguncula brevis use Chesapeake Bay: one class $(<60 \mathrm{~mm} \mathrm{DML})$ uses the bay in the spring through the fall, and a second, less abundant class ( $\geq 70 \mathrm{~mm}$ DML) is most prevalent in the spring. The absence of a distinct intermediate size class $(\sim 60 \mathrm{~mm}$ DML) in Chesapeake Bay in the fall (or at any other time during the year), as was detected in the NMFS/NEFSC surveys performed along the Atlantic coast, suggests that $L$. brevis may leave the bay once a specific size is reached and head for coastal waters of the Atlantic Ocean. Heavy utilization of certain habitats by smaller individuals and subsequent migration of larger individuals is common among cephalopods (Whitaker 1980, Hixon 1983, Nesis 1983, Okutani 1983, Summers 1983, Nagasawa et al. 1993, Hanlon \& Messenger 1996).

Limited field observations suggest that larger brief squid may be using Chesapeake Bay as spawning grounds, at least during late July through early September. This is consistent with the study of Vecchione (1982), who found paralarvae near the mouth of Chesapeake Bay during the warmest months of late summer. Within the Gulf of Mexico, spawning occurs to some degree year-round, with peak spawning occurring during April to July and September to November (LaRoe 1967, Hixon 1980, Jackson et al. 1997). More work on fecundity and paralarval ecology needs to be performed in Chesapeake Bay to determine if spawning occurs in the spring (when larger 
Lolliguncula brevis are most abundant), summer, and fall, and if there are peak spawning events throughout the year. Given that statolith studies have revealed that $L$. brevis live approximately 100 to $200 \mathrm{~d}$ in the Gulf of Mexico (Jackson et al. 1997), it is likely that spawning occurs to some degree most of the time that brief squid are in Chesapeake Bay. Early juveniles that either hatch in Chesapeake Bay or that migrate into the bay from offshore habitats may remain in the bay to exploit its rich food supply, i.e., crustaceans and juvenile finfishes.

The common occurrence of brief squid within Chesapeake Bay, a euryhaline, highly variable environment that is home to hundreds of species of fishes each year, is intriguing. Squid in general are thought to be hampered by a deficient physiology and are notorious for possessing an inefficient means of propulsion. Consequently, squid are thought to have evolved in environments such as deep-sea or offshore, pelagic habitats where interaction with more efficient nekton is minimized (O'Dor \& Webber 1986, Wells 1994). Nonetheless, brief squid are present in an inshore, physiologically taxing habitat rich with nektonic fauna. Further research into the physiology and locomotive abilities of brief squid, especially the smaller individuals that appear to be most abundant within Chesapeake Bay, may further our evolutionary and ecological understanding of this unique cephalopod.

Acknowledgements. We thank M. R. Patterson, S. L. Sanderson, W. M. Kier, and M. Luckenbach for intellectual input and constructive comments on earlier drafts. We also thank members of the VIMS Trawl Survey for data collection, especially P. Geer, who also assisted in the retrieval of trawl data on squid. Financial support for the VIMS Trawl Survey was provided by Wallop Breaux and the U.S. Fish and Wildlife Service Sportfish Restoration Project F104. Financial support during the writing phase of this manuscript was provided by the Office of Naval Research under contract N00014-96-0607 to M.S. Gordon.

\section{LITERATURE CITED}

Agresti A (1990) Categorical data analysis. John Wiley \& Sons, Inc., New York

Bartol IK, Mann R, Patterson MR (2001a) Aerobic respiratory costs of swimming in the negatively buoyant brief squid Lolliguncula brevis. J Exp Biol 204:3639-3653

Bartol IK, Patterson MR, Mann R (2001 b) Swimming mechanics and behavier of the negatively buoyant, brief squid Lolliguncula brevis. J Exp Biol 204:3655-3682

Brandt A, Sarabun CC, Seliger HH, Tyler MA (1986) The effects of a broad spectrum of physical activity on the biological processes in the Chesapeake Bay. In: Nihoul JCL (ed) Marine interface ecohydrodynamics, Elsevier, Amsterdam, p 361-284

Dragovich A, Kelly JA Jr (1967) Occurrence of the squid, Lolliguncula brevis, in some coastal waters of western Florida. Bull Mar Sci 17:840-844
Finke E, Pörtner HO, Lee PG, Webber DM (1996) Squid (Lolliguncula brevis) life in shallow waters: oxygen limitation of metabolism and swimming performance. J Exp Biol 199: 911-921

Geer PJ, Austin HM (1995) Juvenile fish and blue crab stock assessment program bottom trawl survey annual data summary report. Special Scientific Report no. 124: vol. 1995, College of William and Mary, School of Marine Science, Virginia Institute of Marine Science, Gloucester Point, VA 23062

Hanlon RT, Messenger JB (1996) Cephalopod behaviour. Cambridge University Press, Cambridge

Hendrix JP Jr, Hulet WH, Greenberg MJ (1981) Salinity tolerances and the response to hypoosmotic stress of the bay squid Lolliguncula brevis, a euryhaline cephalopod mollusc. Comp Biochem Physiol 69A:641-648

Hixon RF (1980) Growth, reproductive biology, distribution and abundance of three species of loliginid squid (Myopsida, Cephalopoda) in the Northwest Gulf of Mexico. PhD thesis, University of Miami, Miami

Hixon RF (1983) Loligo opalescens. In: Boyle PR(ed) Cephalopod life cycles, Vol. 1. Species accounts. Academic Press Ltd, London, p 95-114

Hosmer DW, Lemeshow S (1989) Applied logistic regression. John Wiley \& Sons, Inc. New York

Jackson GD, Forsythe JW, Hixon RF, Hanlon RT (1997) Age, growth, and maturation of Lolliguncula brevis (Cephalopoda: Loliginidae) in the northwestern Gulf of Mexico with a comparison of length-frequency versus statolith age analysis. Can J Fish Aquat Sci 54:2907-2919

Laughlin RA, Livingston RJ (1982) Environmental and trophic determinants of the spatial/temporal distribution of the brief squid (Lolliguncula brevis) in the Apalochicola Estuary (North Florida, USA). Bull Mar Sci 32:489-497

LaRoe ET (1967) A contribution to the biology of the Loliginidae (Cephalopoda: Myopsida) of the tropical western Atlantic. Master's thesis, University of Miami, Miami

Mangum CP (1991) Salt sensitivity of the hemocyanin of euryand stenohaline squids. Comp Biochem Physiol A 99: 159-161

Mickey J, Greenland S (1989) A study on the impact of confounder-selection criteria on effect estimation. Am J Epidemiol 129:125-137

Nagasawa K, Takayanagi S, Takami T (1993) Cephalopod tagging and marking in Japan: a review. In: Okutani T, O'Dor RK, Kubodera T (eds) Recent advances in cephalopod fisheries biology. Tokai University Press, Tokyo, p 313-329

Nesis KN (1983) Dosidicus gigas. In: Boyle PR (ed) Cephalopod life cycles, Vol. 1. Species accounts. Academic Press Ltd, London, p 215-231

O'Dor RK, Webber DM (1986) The constraints on cephalopods: why squid aren't fish. Can J Zool 64:1591-1605

O'Dor RK, Durward RD, Balch N (1977) Maintenance and maturation of squid (Illex illecebrosus) in a 15-m circular pool. Biol Bull (Woods Hole) 153:322-335

O'Dor RK, Hoar JA, Webber DM, Carey FG, Tanaka S, Martins H, Portiero FM (1994) Squid (Loligo forbesi) performance and metabolic rates in nature. Mar Freshw Behav Physiol 25:163-177

O'Dor RK, Aitken JP, Andrade Y, Finn J, Jackson GD (2001) Currents as environmental constraints on the behavior, energetics and distribution of squid and cuttlefish. Bull Mar Sci (in press)

Okutani T (1983) Todarodes pacificus. In: Boyle PR (ed) Cephalopod life cycles, Vol. 1. Species accounts. Academic Press Ltd, London, p 201-214

Pinet PR (1992) Oceanography: an introduction to the planet 
oceanus. West Publishing Company, St. Paul, MN

Roper CFE, Sweeney MJ, Nauen CE (1984) FAO species catalogue, Vol. 3. Cephalopods of the world. An annotated and illustrated catalogue of species of interest to fisheries. FAO Fish Synop, No. 125, Vol. 3, 277 p

Summers WC (1983) Loligo opalescens. In: Boyle PR (ed) Cephalopod life cycles, Vol. 1. Species accounts. Academic Press, London, p 115-142

Vecchione M (1982) Larval distribution of a euryhaline squid near its northern range limit. Bull Am Malacol Union 81:36

Vecchione M (1991a) Dissolved oxygen and the distribution of the euryhaline squid Lolliguncula brevis. Bull Mar Sci 49: 668-669

Vecchione M (1991b) Observations on the paralarval ecology of a euryhaline squid Lolliguncula brevis (Cephalopoda: Loliginidae). Fish Bull (Wash DC) 89:515-521

Vecchione M, Roper CF (1991) Cephalopods observed from submersibles in the western North Atlantic. Bull Mar Sci 49:433-445

Editorial responsibility: Kenneth Sherman (Contribution Editor), Narragansett, Rhode Island, USA
Vecchione M, Roper CF, Sweeney MJ (1989) Marine flora and fauna of the eastern United States mollusca: Cephalopoda. NOAA Tech Rep NMFS 73:23

Webb KL, D'Elia CF (1980) Nutrient and oxygen redistribution during a spring neap tidal cycle in a temperate estuary. Science 207:983-985

Wells MJ (1994) The evolution of the racing snail. Mar Freshw Behav Physiol 25:1-12

Wells MJ, Hanlon RT, Lee PG, Dimarco FP (1988) Respiratory and cardiac performance in Lolliguncula brevis (Cephalopods, Myopsida): the effects of activity, temperature, and hypoxia. J Exp Biol 138:17-36

Whitaker JD (1980) Squid catches resulting from trawl surveys off the southeastern United States. Mar Fish Rev 42:39-43

Zielinski S, Lee PG, Pörtner HD (2000) Metabolic performance of the sguid Lolliguncula brevis (Cephalopoda) during hypoxia: an analysis of the critical PO2. J Exp Mar Biol Ecol 243:241-259

Submitted: June 1, 2000; Accepted: March 13, 2001 Proofs received from author(s): January 15, 2002 